\title{
EL TEXTO DE AGUSTÍN, CONFESIONES 9.11.28. CONSIDERACIONES LITERARIAS, FILOSÓFICAS, Y MÉTRICAS.
}

\author{
Alfredo P. Encuentra Ortega \\ Universidad de Zaragoza \\ alfenc@unizar.es
}

SUMMARY

We discover striking similarities between

Conf. 9.11.28 and some Carmina Latina epigraphica in their topics, language and rhythm. The connection of this text with Conf. 1.13.21, both in the discussion of the two kinds of Platonic love and the allegorical tension with the Aeneid, reinforces our supposition that Conf. 9.11.28 contains an hexametric line.

KEYWORDS

Augustine. Confessions. Love.
RESUMEN

El análisis del pasaje de Conf. 9.11.28 revela una gran proximidad con la poesía epigráfica en sus tópicos, su lenguaje y su configuración rítmica. Se analiza la posibilidad de restaurar un hexámetro que habría quedado oculto por una falta de copista. La fuerte dependencia temática con Conf. 1.13.21 respecto al tema platónico del amor y la tensión alegórica con la trama de Enei$d a$ corrobora esta posibilidad.

Palabras Clave

Hexameter
Agustín. Confesiones. Amor. Hexámetro.

Fecha de recepción: 23/03/2012

Fecha de aceptación y versión final: 28/08/2012

Agustín dedica la mayor parte del libro 9 de sus Confesiones a relatar la muerte de su madre Mónica. En el momento de morir, ella se hallaba a las afueras de Ostia, esperando a que las rutas marítimas fuesen abiertas y pudiese volver a su África natal junto a su hijo. En efecto, Mónica había seguido los pasos de Agustín desde Cartago hasta Milán ${ }^{1}$ y con él había participado en el famoso retiro de Casiciaco. Finalizado éste, ambos habían regresado a Roma²

${ }^{1}$ P. Courcelle (Recherches sur les Confessions de saint Augustin, Paris 1968², 87) sitúa la llegada de Mónica en junio del 385. Seguramente viajó acompañada de su otro hijo Navigio y de sus sobrinos Lartidiano y Rústico.

${ }^{2}$ Sobre la segunda estancia de Agustín en Roma, de la que éste guarda un misterioso silencio en Confesiones, y la actividad intelectual que allí desarrolló, cf. Courcelle, Recherches, 227-33. 
y su puerto. Estamos entonces entre el verano del 387 y el del 388, cuando la navegación había quedado interrumpida por el peligro que suponían la flota y el avance del usurpador Máximo.

La primera parte de este relato adquiere el tono de laudatio funebris por cuanto Agustín realiza una semblanza de las virtudes de Mónica como hija, esposa y madre ${ }^{3}$. Así se narra en primer lugar la austeridad de su educación en la infancia y la famosa anécdota de cómo detuvo su afición de beber vino puro tras el reproche de la sierva que la acompañaba a buscarlo. En segundo lugar se relata la actitud sumisa de Mónica respecto a su esposo y a su suegra, y cómo su talante pacífico y tolerante hizo que el primero se convirtiese al cristianismo y la segunda la respetase tras superar algunos malentendidos. Este largo pasaje, en el que se aprecia uno de los tópicos epigráficos laudatorios de la matrona romana (su condición de uniuira) ${ }^{4}$, culmina en 9.9.22 en estas expresiones lapidarias, que se entremezclan con el modelo de viuda cristiana que propone 1 Timoteo 5.4 y 9-10:

Erat enim serua seruorum tuorum. Quisquis eorum nouerat eam, multum in ea laudabat et honorabat et diligebat te, quia sentiebat praesentiam tuam in corde eius sanctae conuersationis fructibus testibus. Fuerat enim unius uiri uxor, mutuam uicem parentibus reddiderat, domum suam pietate tractauerat, in operibus bonis testimonium habebat. Nutrierat filios totiens eos parturiens, quotiens abs te deuiare cernebat.

"Era incluso sierva de tus siervos. Cualquiera de ellos que la conocía alababa muchas cosas en ella, y te honraba y te respetaba, porque sentía tu presencia en su corazón con los frutos de su santo trato como testigos. Y es que había sido esposa de un solo hombre, había devuelto a sus padres la obligación recíproca, había dirigido su casa piadosamente, tenía la prueba en sus buenas obras. Había nutrido a sus hijos pariéndolos tantas veces cuantas percibía que se desviaban de ti”.

A continuación, el relato se dedica a describir los momentos previos a la muerte de Mónica, sobre todo a mostrar su satisfacción por haber cumpido el sueño de asistir a la conversión de su hijo y a enfatizar su consiguiente desprecio por la vida, sobre todo después de una conversación mística en que

\footnotetext{
${ }^{3}$ Véase al respecto el trabajo de Ma. M. Agudo Romeo, "El elogio a una mujer cristiana del s. IV: santa Mónica según las Confesiones", Actas del IX Simposio de la Sociedad Española de Literatura General y Comparada (Zaragoza, 18-21 de noviembre de 1992). Tomo I: elogio y vituperio, Zaragoza 1994, 21-6. $30-5$.

${ }^{4}$ Entre los ejemplos epigráficos se pueden citar CIL 6.11602; 1.1007 o el Elogio de Turia

${ }^{5}$ Texto tomado de nuestra traducción, San Agustín. Confesiones, Madrid 2010.
} 
madre e hijo rozan por un instante la contemplación de la Verdad. Justo en el momento de morir (9.11.27), se relata cómo ésta, frente a la mentalidad de la época, expresa su deseo de ser enterrada en Ostia o dondequiera que le llegue la muerte, no en su Tagaste natal, junto a la tumba de su esposo Patricio. La posibilidad de que Mónica, una vez muerta, no recibiese en su patria, y por parte de su familia, las atenciones habituales en unos Parentalia ya cristianizados -a los que, por otra parte, ella tributaba especial devoción ${ }^{6}$ - no sorprendía tanto a Agustín como el cambio de actitud de Mónica, que hasta entonces se había desvelado por prepararse un sepulcro junto a su esposo (ibid. 28):

Quia enim ualde concorditer uixerant, id etiam uolebat, ut est animus humanus minus capax diuinorum, adiungi ad illam felicitatem et commemorari ab hominibus, concessum sibi esse post transmarinam peregrinationem, ut coniuncta terra amborum coniugum terra tegeretur.

"Pues porque habían vivido en enorme concordia, quería también -siendo como es el espíritu humano menos capaz de las cosas divinas- que esto le fuese añadido a aquella felicidad, y que la gente recordase que después de un viaje al otro lado del mar le había sido concedido que la tierra unida de ambos cónyuges con tierra fuese cubierta”.

Curiosamente, la redacción de las últimas palabras del texto latino (terra tegeretur) recuerdan un final de hexámetro. ¿Cabría entonces la posibilidad de que Agustín, versado grammaticus y rhetor, estuviese evocando un hexámetro típico de la epigrafía, o incluso reproduciendo, con las faltas y licencias frecuentes en los "hexámetros africanos" coetáneos, el que su madre tenía preparado para su tumba? De esta forma estaría poniendo el sello definitivo a un pasaje muy marcado por el estilo de la laudatio funebris epigráfica. Antes de descender al terreno de la métrica para constatar una u otra posibilidad, creemos más oportuno comenzar con el análisis de otros elementos de índole temática y formal que otorgarían un color lapidario (y por ende hexamétrico) a este pasaje. Y es que, además del contexto narrativo que acabamos de describir, el pasaje concluye con tópicos frecuentes en los Carmina Latina epigraphica aplicados a los epitafios de matronas.

${ }^{6}$ Léase al respecto Conf. 6.2.2, que narra cómo Mónica, instalada en Milán y dispuesta a participar del culto a los difuntos al modo africano, ofreciendo comida y vino, cedió sin rechistar a la prohibición de Ambrosio por la admiración que le profesaba. Sobre la cristianización de la celebración de los Parentalia, cf. J. Quasten, "Vetus superstitio et nova religio. The problem of refrigerium in the ancient church of North Africa", HThR 33, 1940, 253-66. 


\section{LOS TÓPICOS CARACTERÍSTICOS DE LA LAUDATIO FUNEBRIS}

Se trata en concreto de los tópicos del viaje transmarino, de la concordia de los cónyuges, y, especialmente, de la tumba común de los esposos, prolongación post mortem del tálamo desierto. Del primero, y como variación del frecuentísimo tópico del viaje ${ }^{7}$, podemos citar un epígrafe hallado en Roma (CLE 546, vv. 1-4) que, salvando las distancias, se ajusta bastante a la aventura de Mónica en pos de su hijo huido ${ }^{8}$ Italia, pues como cuenta, ésta hubo de enfrentarse a los peligros de una tempestad al seguirle por tierra y por mar (Conf. 6.1):

Me propter maria, terras atque aspera caeli sidera trasisti (sic) mediosque timenda per hostes inuenisti uiam, hiemis nefanda tulisti, o dulcis coniunx animo gratissima nostro.

"Por mi causa atravesaste mares y tierras y las inaccesibles estrellas del cielo; y temeraria en medio de los enemigos encontraste el camino de salida, soportando los horrores indecibles del invierno, oh mi dulce esposa queridísima de todo corazón"10.

Los dos tópicos siguientes suelen aparecer unidos ${ }^{11}$, como en esta inscripción de Madaura (CLE 1969, vv. 1-3, siglos II-III d. C), que habla de concordes y iunctae animae:

Concordes animae quondam, cum uita maneret, moribus eximiis pariles et amore iugali

sedibus his iunctae per saecula longa quiescunt

"Almas concordes en tiempos pasados, cuando aún vivían, iguales en sus buenas costumbres y en el amor conyugal, unidas en este lugar, descansan por muchos siglos".

${ }^{7}$ Cf. P. Cugusi, Aspetti letterari dei Carmina Latina epigraphica, Bologna 1996, 217-21.

${ }^{8} \mathrm{~J}$. D. Beduhn, "Augustine accused: Megalius, manichaeism, and the inception of the Confessions", JECS 17, 2009, 96, pone su salida apresurada de Cartago, datada aproximadamente en el 383, en relación con el endurecimiento de la legislación antimaniquea en los años 381 al 383. En ella se negaba a los maniqueos el derecho de propiedad, se les exponía a delatores y amenazaba con penas de muerte o exilio, siendo muy dura contra los que se habían convertido al maniqueísmo desde la fe nicena o habían hecho proselitismo promaniqueo, como era el caso de Agustín.

${ }^{9}$ Con la cita de Aen. 9.492 Agustín está evocando en Conf. 6.1 el caso de la madre de Euríalo, que siguió a su hijo desde Troya hasta Italia.

${ }^{10}$ En este y en los siguientes epígrafes de los $C L E$ seguimos la traducción de C. Fernández Martínez, Poesía epigráfica latina, 2 vols., Madrid 1998 y 1999.

${ }^{11} \mathrm{Cf}$. R. Hernández Pérez, Poesía latina sepulcral de la Hispania romana. Estudio de los tópicos y sus formulaciones, Anejo n XLIII de Cuadernos de Filología, Valencia 2001, 131-2. 
Un breve y bello ejemplo de la unión de los coniuges más allá de la muerte aparece en una inscripción cesaraugustana, hoy perdida (CLE 1139A):

Seruaui thalamum genio, dulcissime coniunx: seruandus nunc est pro thalamo tumulus.

"Velé por nuestro lecho matrimonial con todo mi corazón, queridísimo esposo: y ahora, en lugar de por el lecho, tengo que velar por la tumba".

Aparte de ilustrar el mismo tópico, este epígrafe resulta de especial interés por su políptoto, su paralelismo y la aliteración, recursos que aparecen también en el pasaje agustiniano que nos ocupa. En él la disposición retórica es sorprendentemente idéntica: un doble políptoto (el evidente terra... terra, y otro más laxo pero con la misma base etimológica coniuncta ... coniugum) dispuesto mediante paralelismo, y un final aliterante terra tegeretur. Más que deberse a la casualidad, parecen obedecer a una decidida voluntad artística de imitar el estilo del epigrama fúnebre.

\section{AMOR MÁS ALLÁ DE LA MUERTE}

Aparte de epígrafes como éste, el tópico de la unión de los amantes más allá de la muerte se halla presente en algunos textos literarios donde aparece como resultado final de un tipo de amor sobre el que Agustín reflexiona en sus Confesiones. Nos referimos, en primer lugar, a la célebre historia de Píramo y Tisbe (Ov. met. 4.161-5). Tisbe, muriendo por no poder vivir sin Píramo y desafiando a la muerte al morir (quique a me morte reuelli / heu! sola poteras, poteris nec morte reuelli), pide a los padres de ambos que no rechacen sepultar unidos a quienes unieron amor y muerte (ut quos certus amor, quos hora nouissima iunxit, / conponi tumulo non inuideatis eodem). Sus súplicas son atendidas y sus cenizas reposan juntas en una sola urna: quodque rogis superest, una requiescit in urna.

Otro antecedente literario de cuyo conocimiento por parte de Agustín queda constancia es el relato de Cárite y Tlepólemo, tal como aparece en el Asno de oro $^{12}$. Cárite, afligida por la muerte de su joven esposo y por el conocimiento de la traición del asesino Trasilo, el cual la acucia sin cesar para que le otorgue su mano, resuelve suicidarse sobre la tumba de Tlepólemo. Antes se ha vengado de Trasilo, sajándole los ojos. Éste, a su vez, se deja morir de hambre en un sepulcro. Los allegados de Cárite la depositaron allí con su esposo a modo de tálamo perpetuo: tunc propere familiares miserae Cha-

${ }^{12}$ En La ciudad de Dios 18.18 Agustín alude al Asno de oro al abordar la creencia sobre hechiceras que convertían a viajeros en asnos pero sin que fuese alterada su mente humana y racional. 
rites accuratissime corpus ablutum inunita sepultura ibidem marito perpetuam coniugem reddidere (8.14).

Esta última historia tiene un estrecho paralelismo con la de otra desdichada, la misera Dido virgiliana, la cual nos remite de vuelta al texto agustiniano al tiempo que lo ilumina. En efecto, justo antes de morir, suicidándose por no poder vivir sin Eneas, ve cumplidas sus expectativas de vida, que esboza en forma de epigrama funerario (Aen. 4.653-6):
Vixi et quem dederat cursum Fortuna peregi
et nunc magna mei sub terras ibit imago.
Vrbem praeclaram statui, mea moenia uidi,
ulta uirum poenas inimico a fratre recepi.
"He vivido, y he cumplido el rumbo que Fortuna me había marcado, y es hora de que marche bajo tierra mi gran imagen.
He fundado una ciudad ilustre, he visto mis propias murallas, castigo impuse a un hermano enemigo tras vengar a mi esposo"13.

Aunque declara haber vengado la muerte de su esposo Siqueo, reconoce morir inulta de la afrenta de Eneas (Aen. 4.659). A diferencia de las anteriores, en esta historia falta la unión física de los amantes post mortem, si bien se produce un encuentro en en Hades entre la sombra de la desdichada y el troyano.

Precisamente ese mismo encuentro aparece aludido en Conf. 1.13.21. Agustín lo introduce en un pasaje en que critica el contenido de la educación recibida en su niñez, que le incitaba a llorar a Dido y a no lamentar las malas costumbres en las que era educado, dirigidas al éxito material y social. Para ello cita uno de los versos procedentes del momento en que Eneas, en su recorrido por los infiernos (Aen. 6.457), tras encontrarse con el espectro silente de la misera Dido, estalla en lágrimas e intenta disculparse ante ella que, con la mirada fija en el suelo, le va siguiendo los pasos.

\begin{abstract}
Quid enim miserius misero me non miserante se ipsum et flente Didonis mortem, quae fiebat amando Aenean, non flente autem mortem suam, quae fiebat non amando te, deus, lumen cordis mei et panis oris intus animae meae et uirtus maritans mentem meam et sinum cogitationis meae? Non te amabam et fornicabar abs te et fornicanti sonabat undique «euge, euge». Amicitia enim huius mundi fornicatio est abs te et «Euge, euge» dicitur, ut pudeat, si non ita homo sit. Et haec non flebam, et flebam Didonem extinctam ferroque extrema secutam sequens ipse extrema condita tua relicto te et terra iens in terra.
\end{abstract}

${ }^{13}$ Traducción de R. Fontán Barreiro, Madrid 1998. En ella preferimos traducir cursum por 'rumbo' para destacar la metáfora marinera. 
“¿Qué hay en realidad más miserable que un miserable que no siente conmiseración de sí mismo y que llora la muerte de Dido, que se producía por amar a Eneas, sin llorar, en cambio su propia muerte, que se producía por no amarte a ti, Dios, luz de mi corazón, y pan interior de la boca de mi alma, y virtud que une en matrimonio mi mente y el pliegue interno de mi pensamiento? No te amaba, y fornicaba apartado de ti y, al fornicar, de todas partes me llegaba el eco del «ibravo, bravo!», pues el apego a este mundo es fornicar apartado de ti, y ese «ibravo, bravo!» se dice para producir vergüenza, de no ser así el ser humano. Y no lloraba estas cosas y lloraba a Dido, DIFUNTA Y QUE CON LA ESPADA HABÍA LLEGADO A LO PEOR mientras yo llegaba a lo peor en tus mandatos, después de abandonarte, y mientras yo, tierra, caía a la tierra”.

Agustín compara alegóricamente esta escena con su conducta hacia Dios en su niñez. Como demuestra C. Bennet ${ }^{14}$, Agustín lee y reinterpreta la Enei$d a$ en sus Confesiones como texto que refleja cierto grado de verdad universal si es interpretada en relación con la vivencia personal, con el alma humana, a la que considera sede de dicha verdad. Así, en lo que atañe a la vida del alma, Agustín tenía su mirada apartada de Dios; usando una metáfora erótica, le era infiel, de ahí que necesitase girarse, se conuertere. El concepto 'tierra' aparece aquí como emblema de los seres de la creación, a los que se apega el alma y por cuya pérdida lloraba Agustín en lugar de aspirar a su patria espiritual junto a la divinidad. Esto nos remite al famoso pasaje del Fedro (246 ss.) en el que Platón compara el alma humana con un tiro compuesto de dos caballos alados que un auriga tiene que dirigir: uno tira hacia arriba, ansiando probar el pasto de la Verdad, y el otro tira hacia la tierra, buscando los placeres materiales. A este respecto Agustín declara en Conf. 13.9 .10 que "mi peso es mi amor, me lleva a dondequiera que voy", pues el alma apegada a la tierra pierde conciencia de su origen celeste (Fedro 649b-c). Como declara Platón en varios lugares $^{15}$, el cuerpo es la tumba del alma y, por deducción, también la tierra lo es del cuerpo. Por eso el tagastense duda entre definir su nacimiento físico como llegada a una uita mortalis o a una mors uitalis (Conf. 1.6.7).

14 "The Conversion of Vergil: The Aeneid in Augustine's Confessions", REAug 34, 1988, 47-69, esp. p. 54. De hecho, la lectura y comentario eminentemente alegórico de Eneida formaba parte importante de las actividades en su retiro espiritual en Casiciaco, como Agustín declara en $\operatorname{ord} .8,26$ y se puede apreciar en el transcurso de $c$. acad. (1.5.15 ss.; 2.4.10 y 3.1.1). Eso explica que la epopeya virgiliana sea un importantísimo referente estructural de las Confesiones.

${ }^{15}$ Phaedr. 250c, Phaed. 82e, Rep. 10.611e, Gorg. 493a. La misma idea reproduce Cicerón (rep. 6,19) en el famoso sueño de Escipión en cuanto que la sucesiva caída de la vista en la tierra estando observando la maquinaria celeste y divina se resuelve en la máxima: haec caelestia semper spectato, illa humana contemnito. 


\section{LAS dos Venus: anÁlisis del AMOR EN CONFESIONES}

En este último pasaje hemos llamado la atención sobre la presencia de metáforas eróticas. Y es porque, según creemos, Agustín tiene en mente dos tipos de amor que se remontan a la doctrina que Platón esboza en su Banquete (180c-5c) en boca de Pausanias: el amor hacia los cuerpos hermosos, que patrocina una Afrodita vulgar (pandemos), que concibe y pare en el cuerpo, y un amor hacia las almas hermosas, adscrito a una Afrodita celeste (urania), que buscando el bien de la persona amada, concibe y pare en espíritu. En correspondencia con las diosas hay también dos Eros o Amores. No podemos asegurar que Agustín leyese directamente a Platón ${ }^{16}$, pero sí que conociese doxografías y manuales como el De Platone apuleyano, que distingue (2.13.239) entre un amor qui uulgo amor dicitur, calificado como adpetitus ardens que obliga a los amantes a considerar que la persona amada no va más allá del cuerpo, y otro, divino (2.14.239), propio de personas sensibles (facetae et urbanae) y dirigido a almas de personas buenas con el objetivo de hacerlas mejores y más virtuosas.

Como decíamos, Agustín distingue en sus Confesiones dos tipos de amor. El primero está simbolizado por la tierra y como apego del corazón, sede del alma, a los seres de la creación. Su manifestación más evidente es la costumbre disfrutar y contar con la presencia de la persona amada. Así visto, esta concepción del amor basado en el deseo (concupiscentia) engloba por supuesto las relaciones eróticas pero también a cualquier tipo de amistad. Según relata el tagastense, es el tipo de amor que le unía a su concubina, pero es también el que subyacía en la amistad hacia su anónimo amigo de juventud, esa mitad de su alma (Conf. 4.6.11). La ruptura fue en ambos casos dolorosa, pues la supresión del vínculo del apego, no importa de qué tipo fuese, dejó heridas difíciles de cerrar ${ }^{17}$ : «mi corazón, allí donde se apegaba, estaba desgarrado y herido, y supuraba sangre» (Conf. 6.15.25). En el caso de Mónica era el amor que la unía a su hijo y la hacía caer en súplicas desesperadas para que aquel no

${ }^{16}$ La opinión tradicional de los especialistas es conceder a Agustín unos conocimientos bastante rudimentarios de lengua griega, que éste ampliaría en su madurez en sus lecturas de la patrística griega. En cuanto a posibilidad de que leyese directamente a Platón, el texto de $L a$ vida feliz 1.4 indica que Agustín leyó unos poquísimos libros de Platón (Platonis), pero los editores prefieren la lectura Plotini ('de Plotino') por coherencia interna. No obstante, es seguro que conoció el Timeo en las traducciones latinas de Cicerón y de Calcidio, y posible que leyese el Fedón traducido por Apuleyo. Aunque falten indicios concluyentes, parece que Ambrosio, según infiere P. Courcelle (Recherches, 313) por el tenor literal de las citas, tuvo ante sus ojos el original del Fedro al redactar algunas de sus obras, o cuando menos extractos de él, y no es descabellado pensar que este ejemplar o su copia llegase a Agustín. Sea como fuere, siempre quedan las noticias y referencias obtenidas en tratados y doxografías como los de Cicerón, Varrón o Apuleyo.

${ }^{17} \mathrm{La}$ descripción de cómo se separó de su concubina en Conf. 4.15.25 es sumamente explícita: "una vez arrancada de mi costado -como impedimento para mi matrimonio- aquella con la que solía acostarme, mi corazón, allí donde se apegaba, estaba desgarrado y herido, y supuraba sangre". 
la abandonase y no marchase a Roma; era también el que la unía a su esposo y la animaba a disponer una tumba conjunta.

El cambio de actitud de Mónica hacia su sepultura abre por tanto una dimensión nueva a un amor puramente espiritual y eterno, que no acaba con la muerte, semejante al que describía Cicerón en su perdido Hortensio que tanto influyó en el Agustín joven: el amor hacia lo divino eterno e inmutable. Agustín lo cristianiza en la famosa imagen de Conf. 10.6.8: "Atravesaste mi corazón con tu Palabra, y te amé” y lo llama caritas. Así lo define en $L a$ doctrina cristiana 3.10.16:

Caritatem uoco motum animi ad fruendum deo propter ipsum et se atque proximo propter deum; cupiditatem autem motum animi ad fruendum se et proximo et quodlibet corpore non propter deum.

"Llamo caridad al impulso del alma para disfrutar de Dios en su provecho, y de uno mismo y del prójimo en provecho de Dios; deseo, en cambio, al impulso del alma para disfrutar de uno mismo y del prójimo y de cualquier otro cuerpo pero no en provecho de Dios".

A diferencia del amor esclavizante basado en la concupiscentia, la caritas otorga al alma consciente de su patria divina reposo y liberación. Al igual que el amor carnal, también la caritas concibe y engendra dones espirituales y el hombre nuevo: "iQué tormentos aquellos, los de mi corazón a punto de parir, qué gemidos, Dios mío!” (Conf. 7.8.11).

\section{Alegorías virgilianas en Confesiones}

Como vemos, el concepto terra y el tema del amor establecen una fuerte conexión entre el pasaje de Conf. 1.13.21, que narra la reacción del niño Agustín ante la muerte de Dido, y el relato de la muerte de Mónica (9.11.28) que, en un sentido que intentaremos demostrar, supone un momento culminante en el desarrollo narrativo de Confesiones. Esa conexión se refuerza con la asociación alegórica entre las figuras de Dido y Mónica -las abandonadas pedisequae-, por un lado, y las de Eneas y Agustín -los que dan la espalda-, por otro. Desde este punto de vista, el peculiar juego alegórico entre la pareja de amantes Dido y Eneas y la que forman Mónica y Agustín aparece como una forma de plasmar la evolución espiritual de estos último y, aún más, el proceso de conversión del propio Agustín. En este sentido, esa conversión no supone la culminación total de la evolución espiritual o del retorno del alma a su origen, pues aún le quedan por delante unos grados hasta que ésta recobre la semejanza con la divinidad.

Efectivamente, esta asociación es muy visible en el relato del libro quinto de Confesiones, que describe cómo Agustín parte a escondidas hacia Roma 
desatendiendo las súplicas y ruegos de su madre, que queda engañada y abandonada en el puerto de Cartago (Conf. 5.8.15) como Dido mucho tiempo atrás. Dicho vínculo se extiende además a toda la trama de Conf. si tenemos en cuenta que Agustín pretende narrar en ellas, al igual que Virgilio en Enei$d a$, el viaje de búsqueda de la patria perdida. Eneas va en pos del origen de la estirpe troyana; el alma de Agustín tras su patria divina, que en Conf. 12 se identifica con el Cielo del Cielo de Salmos 113, 23 (15)-24 (16). En ambos casos, esa búsqueda es la historia de los extravíos (errores), las zozobras y las tempestades ${ }^{18}$ que jalonan un viaje azaroso pero, al mismo tiempo, guiado por una divinidad providente.

Por lo que respecta a Mónica, no sólo llora y sufre por el abandono y la separación del vínculo físico con su hijo, sino también por las zozobras del alma de aquél. No obstante, la asimilación de Mónica a Dido concluye en el momento en que la desesperación de aquélla no desemboca en la tragedia de ésta sino en una victoria espiritual tras una resistencia pasiva muy parecida a la de la Penélope odiseica ${ }^{19}$, convirtiéndose en progenitora espiritual de Agustín, como se apreciaba en el texto analizado de Conf. 9.9.22.

Tras este cambio de actitud se consolida otra asociación con el universo de la Eneida, la que une a Mónica con la figura de Anquises, progenitor de Eneas. Tal proceder no debe resultarnos tampoco extraño pues, en lo que toca al plano espiritual, Agustín consideraba simultánea e igualitaria la creación del hombre y la mujer, no así en el plano temporal y corporal (Conf. 13.32.47 $)^{20}$ donde aplica a esta última los prejuicios habituales en la Antigüedad. Esta asociación aparece desde las primeras páginas de Confesiones y se solapa con la que, hemos visto, la unía a Dido, pero al final acaba imponiéndose. Efectivamente, Anquises marcaba el rumbo de los viajes de su hijo, actuaba de portavoz de la voz divina manifestada en oráculos y precedía y guiaba a Eneas en sus viajes y, después de morir, en su descenso a los infier-

${ }^{18}$ Efectivamente, el léxico de la navegación es empleado en los siete primeros libros de las Confesiones para describir el viaje del alma de Agustín. Sobre estas y otras imágenes cf. J. Fontaine, "Sens et valeur des images dans les Confessions", Augustinus magister. Congrès International Augustinien (Paris 21-24 sept. 1954), Paris 1955, 117-26.

${ }^{19}$ Además de la Eneida, Agustín parece tener también en cuenta la Odisea, que conocía desde la escuela del grammaticus, tal como relata en Conf. 1.14.23. Además, la espiritualización alegórica de esta obra está presente ya, entre otras obras griegas, en los tratados neoplatónicos que tanto impresionaron al Tagastense (Plotino, Enéadas 1.6.8,) y creo descubrirlo también, aunque e contrario, a propósito del episodio de Ulises y las sirenas en el relato de la afición de Alipio por los juegos de gladiadores (Conf. 6.8.13).

${ }^{20}$ De hecho, la figura de Patricio, el "padre de su carne» apenas recibe unas breves y críticas menciones a lo largo de la obra (Conf. 2.3, 6; 9.9.19). Como padre de su espíritu aparece más bien Mónica, quien en 9.4.8 es descrita como participante activa en el retiro de Casiciaco "con su apariencia de mujer, lealtad de varón, seguridad de anciana, cariño de madre, piedad de cristiana”. En este sentido, unos capítulos más adelante, en 9.11.28, justo el pasaje que nos ocupa, Agustín destaca la "hombría" (uirtus) de Mónica por superar el pavor de morir y dejar su cuerpo lejos de su patria. 
nos. De igual modo actúa Mónica en la Odisea espiritual de Confesiones, cuando desde los primeros años encarrila a su hijo en el cristianismo niceno, que él luego abandona por el maniqueo. Asimismo, ante los errores de éste, Mónica obtiene el consuelo de dos oráculos: el primero en forma de sueño (Conf. 3.11.19) en el que un joven resplandeciente se aparece ante ella, que estaba erguida sobre una regla niveladora, y le anuncia que "donde esté ella también estará Agustín”; el segundo salido de la boca de cierto obispo católico, antiguo maniqueo, que, ante la insistencia y desesperación de Mónica, despacha a esta última afirmando que "no era posible que se echara a perder el hijo de esas lágrimas" ${ }^{21}$. Por último, y justo antes del pasaje que nos ocupa (Conf. 9.10.23-5), en la conversación que mantienen madre e hijo cerca de Ostia, ambos van ascendiendo grado a grado hacia Lo que es, a una fugaz contemplación mística, en la que pierden valor todos "los deleites de los sentidos de la carne" 22 . Es una antesala del descenso a las profundidades del espíritu-al depósito donde el alma guarda los recuerdos últimos de su anterior estado, la contemplación de la divinidad- que realiza Agustín en el libro 10, y a la exégesis del comienzo del Génesis que a partir de ese momento realiza en los libros 11, 12 y 13, dedicados a descubrir a Dios como Creador, como Palabra y como Espíritu.

\section{ALEgoría INTERNA: MUERTE Y RESURRECCIÓN}

Si nos hemos detenido y casi extraviado en estos detalles ha sido para comprender mejor el valor del libro 9 de Confesiones como reverso de la situación narrada en el libro 1, dedicado al nacimiento y la infancia de Agustín. Y es que el libro 9 se presenta en la acertada definición de J. O’Donnell ${ }^{23}$, como libro de muerte y renacimiento (death and rebirth), tanto de Agustín como de Mónica. Muere el viejo Agustín-Eneas y, tras su conversión (Conf. 8.12.29) y bautismo, nace uno nuevo alumbrado en lo espiritual por Mónica; también muere la vieja Mónica-Dido apegada a su hijo y a su esposo por un amor terrenal y nace una nueva Mónica espiritual y eterna. Mónica, al igual que Anquises en Cumas con Eneas, presenta y anticipa a su hijo esta eternidad futura en la conversación de Ostia.

En estas coordenadas significativas, el hexámetro que se insinúa en 9.1.28 encarna a la perfección esta evolución de Mónica hacia lo espiritual, por

${ }^{21}$ A estos dos pasajes hay que añadir el relato (Conf. 6.1.1) de cómo Mónica, en el viaje en barco que le llevó de África a Italia, consoló a los viajeros asustados por los peligros de la navegación asegurando que, por revelación divina, tocarían puerto sanos y salvos.

${ }^{22}$ C. Bennett ("The Conversion of Vergil”, 65) descubre más elementos de detalle que relacionan el descenso de Eneas a los infiernos y la ascensión mística de Ostia: en ambos se contempla la vida futura de las almas, ambos se sitúan en un vergel y aparece el agua: la que las almas toman del Leteo en Aen. 6.679-718, y la fuente de la vida hacia la que Agustín y Mónica abren sus bocas en Conf. 9.10.23.

${ }^{23}$ Augustine: Confessions, Oxford 1992, III, 72. 
cuanto desprecia el amor hacia las cosas del mundo pasajero. Ya no busca que la tierra sea unida a la tierra, ya no le preocupa morir en su patria terrenal, puesto que ha contemplado ya su patria espiritual. Por eso, como quiera que, tras caer enferma y sufrir por unos momentos el "abandono de su alma" preguntase si la enterraban en Ostia y Navigio, el hermano de Agustín, le animase a desear morir en Tagaste, exclamó con un tono de sarcasmo: "imira lo que dice!" $(9.11 .27)^{24}$.

Dicho posible hexámetro también encarna la evolución espiritual que aguarda a Agustín. Y es que la muerte de Mónica aparece como proyección vital de su autobiografía, a modo de cierre -aunque en otra persona- de la historia de su vida, historia detenida tras el relato de su conversión efectuada el año trigésimo tercero de su vida (9.11.28). Recordemos aquí la obviedad de que ninguna autobiografía puede ser completa ${ }^{25}$ y que, si uno de los objetivos de Agustín en Confesiones es el de proporcionar en su propia persona un modelo antropológico que pueda oponerse al de los maniqueos ${ }^{26}$, es natural que complete el cuadro de su vida con el de su madre. Recordemos además que Agustín entendía la historia del alma de Mónica como parte de la historia del alma humana universal, de la que él, su alma, participa. Y es que, al morir, Mónica completa las seis etapas de creación espiritual, según se perfilan en el comentario alegórico de los días de la creación realizado en el libro 13, y está ya gozando de la séptima, el sabbath eterno ${ }^{27}$ al que aspira llegar Agustín en la última línea de Confesiones.

Haciendo un resumen de la exégesis alegórica de los días de la creación tal como Agustín la pone en relación con los grados en la evolución del alma (Conf. 13.12.13-38, 53), la tierra firme del primer día son los chiquitines de 1 Corintios 3.1, la infancia desvalida y nutrida con la fe; las aguas marcadas por su amargor representan los no creyentes en el firmamento de la fe, extendido como un libro por encima de la humanidad en el segundo día de la creación; la congregación de las aguas del tercer día y la aparición de plantas con fruto equivalen a las buenas obras; la creación de los luceros en el firmamento durante el cuarto día, corresponde a los creyentes que viven la vida que propone la Escritura; los reptiles y aves de almas vivas del quinto día son los que con sus obras sirven a Dios como praedicatores. Hasta aquí parece haber llegado

${ }^{24}$ Continuando con la evocación virgiliana y sin que el texto literal apunte en esa dirección, ese punto de sarcasmo hacia las convenciones mundanas evoca el célebre verso que esgrimía Ana ante Dido, que se debatía indecisa entre el amor que sentía por Eneas y su papel de viuda uniuira del malogrado Siqueo (Aen. 4.34): Id cinerem aut manis credis curare sepultos?

${ }^{25}$ Cf. R. G. Lewis, "Imperial Autobiography, Augustus to Hadrian”, ANRW II 34. 1., 630.

${ }^{26}$ Cf. J. van Oort, "Augustinus und der Manichäismus" en The Manichaean NOY . Proceedings of the International Symposium, Leuven 1995, 289-307.

${ }^{27}$ El sentido alegórico se explicita en 13.34.49. Sobre este respecto, véase también Gen. $c$. Manich. 25, 43; sobre la repercusión de estas etapas en la estructura de Conf., vid. la Introducción a nuestra traducción, San Agustín. Confesiones, 64-70. 
Agustín en el momento de escribir en torno al 400, a sus 46 años, por cuanto lo hace ya en calidad de obispo de Hipona. El alma viva que produce la tierra en el sexto día de la creación equivale al control total de las emociones, al dominio del cuerpo, a la armonía entre mente y acción en cuanto que la primera piensa y pone en práctica sólo cosas buenas; en suma, al ser humano hecho a imagen y semejanza de Dios. A esta etapa habría llegado Mónica justo antes de morir, tras lo cual completa los estadios de vida espiritual que Agustín, en ese preciso instante, todavía tiene por delante.

Esta evolución confluye en el juego terra... terra tegeretur, y va referida tanto a la madre como al hijo. Por eso, en la narración que sigue a 9.11.28, dedicada al funeral de Mónica y al dolor que sienten sus allegados, especialmente Agustín (Conf. 9.12.29), vemos cómo se secan, ante la madre muerta, las lágrimas que aquél había vertido mucho antes por Dido y por el queridísimo amigo de juventud (Conf. 4.5.10). El entorno considera insólita esta actitud de Agustín (9.12.31), como insólita se consideraba la postura de Mónica hacia su sepultura. A su vez, el llanto espontáneo del niño Adeodato, que su padre reprime, es otra forma de enfatizar cómo el nuevo Agustín ha tomado el testigo espiritual de su progenitora.

\section{CONSIDERACIONES MÉTRICAS}

A lo largo de las páginas precedentes nos hemos esforzado en poner de manifiesto la importancia, el significado y la configuración literaria del pasaje de Conf. 9.11.28 así como su fuerte relación con el de Conf. 1.13.21. El texto de L. Verheijen ${ }^{28}$ y, con él, todos los manuscritos allí considerados ofrecen en Conf. 9.11.28 ut coniuncta terra amborum coniugum terra tegeretur. La secuencia desde el primer terra hasta tegeretur parece un hexámetro, especialmente por su final, pero desde un estricto punto de vista de la métrica clásica no lo es. Los elementos que se oponen son básicamente dos: el hiato que se ha de suponer entre terra y amborum y la estructura prosódica de coniugum, que forma un crético y no el anapesto que el metro requeriría. Pero son dos también los rasgos que abogan por ver un hexámetro en dicha secuencia: el paralelismo con el pasaje de Conf. 1.13.21, que se cierra con un hexámetro virgiliano, y el final excepcional que implica terra tegeretur, característico de la métrica deliberadamente descuidada de la epigrafía.

Efectivamente, aunque las libertades de la poesía epigráfica en general, y la africana en particular, parecen dar cabida a todo tipo de irregularidades ${ }^{29}$,

${ }^{28}$ Sancti Augustini Confessionum libri XIII, Turnhout 1981 (Corpus Christianorum, series Latina XXVII).

${ }^{29}$ Se pueden citar los versos hipérmetros, hipómetros, las inserciones de prosa que interrumpen y alteran el patrón rítmico y todo tipo de faltas en la cantidad vocálica. Léanse a este respecto las conclusiones de la tesis de L. M. Rae, A study of the versification of the African Carmina Latina Epigraphica, Vancouver 1991, 237-67 y el análisis métrico de la inscripción que analiza R. Rebuffat, "Le centurion M. Porcius Iasutchan à Bu Njem (Notes et documents XI)", 
el hiato como licencia quedaba restingido a la posición in arsi, evitándose en la segunda parte del pie espondaico ${ }^{30}$. Por lo tanto, de producirse un hiato en este texto, habría que suponer también un alargamiento de la vocal final. Ahora bien, el primer terra debe ser un nominativo con cantidad breve. $\mathrm{Ha}$ de serlo, en primer lugar, para que tenga sentido la frase, esto es, que sea la tierra de los cónyuges la que es sepultada con tierra, no a la inversa; en segundo lugar, para que el segundo terra, como ablativo en $-\bar{a}$, permita constituir una cláusula. En estas circunstancias, aducir la indiferencia de las Afrae aures respecto a la cantidad prosódica, característica que la poesía epigráfica africana confirma de múltiples formas, no es razón de mucho peso en un sentido o en otro ${ }^{31}$. Sin embargo, una solución sencilla consistiría en suponer una transposición ${ }^{32}$ en el proceso de copia y transmisión textual que habría dado la secuencia coniuncta terra a partir de una secuencia original terra coniuncta. De esa manera aparecería un primer hemistiquio totalmente regular, con un encuentro de vocales muy suave, hasta la cesura pentemímera: ut terra /coniuncta amborum ( - - / - - / - ) coniugum terra tegeretur. En el plano estilístico desaparecería el paralelismo, pero se abriría un bello quiasmo centrado en torno a amborum. La transposición podría haberse debido a una confusión en el dictado interno del copista propiciada por la repetición de terra y por la configuración prosística que rodea el pasaje. No obstante, ninguno de los manuscritos seleccionados por Verheijen apoyan esta restitución.

En cuanto a coniugum, y atendiendo a lo estrictamente fonético, numerosos testimonios epigráficos transmiten formas como coiogi, cougi, cogiugi, codiugi, $\kappa o ́ \zeta o v\langle\varphi\rangle \varepsilon^{33}$ que dan testimonio de una pronunciación coloquial en la que la consonante $/ \mathrm{n} /$ había desaparecido ante la semivocal palatalizada [j]. También se documenta esta pronunciación en formas de la misma raíz como coiunxit $^{34}$. Se puede inferir, por tanto, que coniugum aparecía en la lengua hablada como trisílabo bajo la forma * $\operatorname{coiugu}(m)$, y que podía funcionar como anapesto acentual en un metro rítmico, pues la primera sílaba habría dejado de ser considerada larga. Por otro lado, un crético como coniugum

\footnotetext{
Lybia antiqua n. s. 1, 1995, 101-8.

${ }^{30}$ Cf. nuestro estudio El hexámetro de Prudencio: estudio comparado de métrica verbal, Logroño 2000, 141-2.

${ }^{31}$ Como el propio Agustín reconoce en doct. Christ. 4.10.34, "los oídos africanos no entendían de sílabas breves y largas". A este respecto, J. Herman ("Un vieux dossier réouvert: les transformations du système latin des quantités vocaliques", BSL 77, 1982, 285-302, esp. 289) aprecia en ello un rasgo dialectal del África romana.

${ }^{32}$ Cf. A. Bernabé-F. G. Hernández Muñoz, Manual de crítica textual y edición de textos griegos, Madrid 2010, 30.

${ }_{33}$ Véase $T L L, s$. $u$. coniunx. Sobre la transliteración fonética de estas formas en caracteres griegos, cf. las observaciones de B. Rochette, "IUG-/ ZOU dans une inscription latine écrite en lettres grecques”, $Z P E 115,1997,169-70$.

${ }^{34}$ CLE 950, 9, epígrafe hallado en Pompeya.
} 
tenía muy difícil entrada en el hexámetro dactílico cuantitativo ${ }^{35} \mathrm{y}$, de hecho, no hemos encontrado ningún caso en toda la poesía latina; encontramos, no obstante, dos ejemplos en los hexámetros de Comodiano, cuya versificación es predominantemente rítmica ${ }^{36}$ y un hexámetro epigráfico en que una forma de coniungere aparece como anfíbraco rítmico ( $\left.\_-\checkmark\right)$. Es el caso de CLE 1288, 2 procedente de Cirta, localidad cercana a la patria de Agustín y que éste pudo tomar como modelo para el verso que intentamos reconstruir e, incluso, para otros ${ }^{37}$ :

Quisquis amat coniunx, hoc exsemplo coniungat amore

En este hexámetro cuantitativamente irregular las palabras exemplo y coniungat enmarcan un corte entre lo que deberían ser las dos sílabas breves de un cuarto pie dactílico. Para que este verso se ajuste al esquema hexamétrico hemos de suponer también que hoc y la primera sílaba de exemplo forman las dos breves del dáctilo tercero tras la cesura pentemímera. Estamos ante un caso más de desaparición de las diferencias de cantidad y de aparición de ritmos acentuales que mantienen la apariencia de metros cuantitativos en cuanto que el acento sigue estando en las mismas posiciones y se mantiene el número de sílabas de los hemistiquios ${ }^{38}$. Obsérvese también cómo la primera sílaba de coniunx aparece como semipié espondaico, seguramente por su calidad de sílaba tónica, frente a la primera sílaba de coniungat, cuya calidad postónica la hace ocupar la posición de breve.

A la vista de este verso, y retornando a coniugum, el crético cuantitativo original podría, tras la pérdida de las diferencias de cantidad, funcionar como anapesto $(\mathrm{x} x-)$ en un hexámetro rítmico, pero también como dáctilo, tal como se infiere de una inscripción africana que presenta el crético militum en la posición del quinto dáctilo ${ }^{39}$. Ello es debido a que la estructura acentual x'

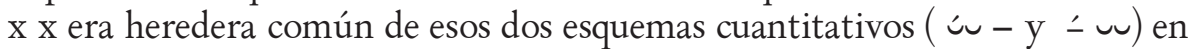

${ }^{35}$ Se requeriría la elisión de la vocal nasalizada (coniug[ũ]-) ante la segunda breve de un dáctilo. Dado que en esa posición se evitan los encuentros de vocales y que sólo se admiten los más suaves, los que contienen una vocal final breve y de igual timbre que la vocal inicial (cf. las leyes que formula al respecto J. Soubiran, L'élision dans la poésie latine, Paris 1966, 510-2), el encuentro que implica la vocal final nasalizada resultaba muy duro y, por tanto, era evitado.

${ }^{36}$ Se trata de Instr. 1.16 .1 (Virginis et Venerem cui coniuges uestrae delumbant) y 2.26.10 (aut natis orbaris aut perdita coniugula defles). Aunque, debido a su naturaleza acentual, parecería un despropósito elucidar el esquema métrico que presentan, en el segundo de los citados versos la primera sílaba de coniugula parece tomarse como la segunda sílaba breve de un cuarto pie dactílico previo a un final hexamétrico regular.

${ }^{37}$ Posidio en su Vita Augustini 22, 6 transmite los dos hexámetros que componían la inscripción que adornaba el comedor de Agustín y amonestaba contra las habladurías: Quisquis amat dictis absentum rodere uitam / hanc mensam indignam nouerit esse suam. Obsérvese que el comienzo coincide con una famosa incripción parietal pompeyana (CLE 945) cuyas variantes (CLE 946, 948, 2056 y 2153) dan muestra de su gran popularidad.

${ }^{38}$ Es lo que, en el caso de la versificación de Comodiano, demuestra J. Perret, "Prosodie et métrique chez Commodien”, Pallas 5, 1957, 27-42.

${ }^{39}$ Cf. R. Rebuffat, "Le centurion M. Porcius”, 101. 
los que la ley del acento latino hacía de ellas esdrújulas, así como, claro está, del crético (- - -). Como en el caso comentado de CLE 1288, Agustín juega con la doble posibilidad de escansión acentual de la raíz co(n)iug- / $\operatorname{co}(n)$ iunc- en el mismo verso ${ }^{40}$.

Pasando ahora a las pruebas positivas de nuestra argumentación, a las consideraciones ya analizadas y referidas a los tópicos epigráficos se suma la calidad de la cláusula final, compuesta por un tetrasílabo del tipo di genuerunt, característica del estilo "descuidado" del hexámetro epigráfico, marcado por una serie de rasgos de inspiración arcaica y coloquial ${ }^{41}$. Ciertamente, éste es un final evitado en toda la poesía hexamétrica latina. Si acudimos a las estadísticas de los estudios de métrica, sólo los hexámetros de Lucrecio, que la depuración formal de poetas posteriores hará aparecer como toscos, ofrecen un porcentaje relevante ${ }^{42}$. Por el contrario, en una colección coetánea de hexámetros epigráficos, los Tituli historiarum que escribe Prudencio como ilustración de un ciclo pictórico de escenas bíblicas, resulta un rasgo relevante y distintivo el porcentaje con que aparece esta cláusula: se prodiga en un $4 \%$ de sus versos frente a 1,8\% de media en todos los hexámetros de Prudencio ${ }^{43}$. Aún moviéndonos en porcentajes tan escasos, se puede apreciar por contraste que es un rasgo permitido y característico del hexámetro epigráfico. La disposición verbal en que se inserta esta cláusula corrobora la impresión de descuido voluntario ${ }^{44}$.

\section{CONCLUSIONES}

A la vista de todas estas consideraciones sólo nos queda decidir si restituimos el hexámetro, introduciendo en el texto un ligero cambio en el orden de las palabras y aceptando el vulgarismo métrico que implica coniugum, o si

${ }^{40}$ Fenómeno frecuente en la poesía antigua. Véase la lista que recoge N. Hopkinson, "Yuxtaposed Prosodic Variants in Greek and Latin Poetry", Glotta 60, 1982, 162-77.

${ }^{41}$ En efecto, a la tosquedad de los primitivos hexámetros epigráficos, que mantienen este rasgo en lo sucesivo, hay que sumar el hecho de que, por lo general, los Carmina Latina epigraphica eran fruto de autores medianamente versados en las leyes de la prosodia.

${ }^{42}$ Esto es lo que se deduce tanto de la tabla comparativa de L. De Neubourg, La base métrique de la localisation des mots dans l'hexamètre latin, Bruxelles 1986, 66 como de nuestro estudio citado en n. 30: la cláusula di genuerunt y su variante Idae)is cyparisis, es un tipo minoritario y el 2,4\% de frecuencia en las cláusulas del hexámetro de Lucrecio deja paso a un 0,4 en Virgilio, un 0,04 en Ovidio, y está ausente en las muestras de Lucano y Papinio Estacio.

${ }^{43}$ A. Encuentra, El hexámetro de Prudencio, 357.

${ }^{44}$ Efectivamente, en el final terra tegeretur no aparecen las precauciones rítmicas a las que los poetas augusteos sometían esta cláusula para neutralizar el corte eneamímero, contrario a la secuencia rítmica que cierra el verso. Y es que no aparecen los paliativos habituales como son introducir un monosílabo ante el tetrasílabo con el que los dos pies finales puedan formar un grupo fonético cohesionado acentualmente, o hacer que el tetrasílabo sea un vocablo helénico al estilo de la épica. Sin embargo, la cláusula resultante no deja de tener cierta cohesión desde heptemímera hasta el final del verso, pero mediante un recurso característico de la tradición epigráfica, la aliteración. 
mantenemos el texto tal y como está y nos limitamos a resaltar su color epigráfico. La cautela nos lleva a no decantarnos definitivamente por la primera opción y nos contentamos con haber ofrecido una serie de consideraciones que esperamos sean tenidas en cuenta por futuros editores de Conf. En todo caso, alteremos el orden de la secuencia o no, no tenemos la menor duda en reconocer que la voluntad estética de Agustín en este pasaje era la de evocar, tanto en la configuración métrica como la argumental, un característico y tosco hexámetro epigráfico y establecer así un vínculo con las cuestiones que había tratado al inicio de sus Confesiones. 
